\title{
Usefulness Analysis of Fraction of Exhaled Nitric Oxide for the Differential Diagnosis of Acute Cough
}

\author{
TAKEO NAKAJIMA ${ }^{1}$, TATSUYA NAGANO ${ }^{2}$, TERUAKI NISHIUMA ${ }^{3}$, \\ KYOSUKE NAKATA ${ }^{2}$ and YOSHIHIRO NISHIMURA ${ }^{2}$ \\ ${ }^{1}$ Nakajima Medical Clinic, Kobe, Japan; \\ ${ }^{2}$ Division of Respiratory Medicine, Department of Internal Medicine \\ Kobe University Graduate School of Medicine, Kobe, Japan; \\ ${ }^{3}$ Department of Respiratory Medicine, Kakogawa Central City Hospital, Kakogawa, Japan
}

\begin{abstract}
Background/Aim: Measuring the fraction of exhaled nitric oxide ( $F e N O)$ is useful in the diagnosis of asthma and cough variant asthma. The aim of this study was to clarify the significance of measuring the FeNO in the differential diagnosis of acute cough. Patients and Methods: We analyzed 80 patients who visited the clinic with the chief complaint of acute cough having experienced an asthma-like episode from January 2014 to July 2015. Results: Infectious cough alone was present in $21 \%$ of patients, while $30 \%$ had asthmatic cough alone and 49\% had a combination of infectious and asthmatic cough. The values of FeNO in those with asthmatic cough $(30.4 \pm 24.7 \mathrm{ppb})$ and asthmatic/infectious cough $(33.2 \pm 17.4 \mathrm{ppb})$ were significantly higher than those with just infectious cough $(13.7 \pm 3.2 \mathrm{ppb})(p=0.0089$ and $p<0.0001$, respectively). Conclusion: FeNO measurement is useful for distinguishing asthmatic diseases, even in the differential diagnosis of acute cough.
\end{abstract}

Coughing is one of the most common motives for patients to visit clinics. Approximately $70 \%$ of acute coughs that occur within 3 weeks are reported to be infectious (1). As the duration of cough increases, the frequency of infection, being the cause of the cough, decreases, and infections rarely cause chronic cough that continues for 8 weeks. Acute cough is often caused by a common cold or an upper respiratory tract

This article is freely accessible online.

Correspondence to: Tatsuya Nagano, Division of Respiratory Medicine, Department of Internal Medicine, Kobe University Graduate School of Medicine, 7-5-1 Kusunoki-cho, Chuo-ku, Kobe, 650-0017, Japan. Tel: +81 783825660, Fax: +81 783825661, e-mail: tnagano@med.kobe-u.ac.jp

Key Words: Acute cough, fraction of exhaled nitric oxide, infectious cough, asthmatic cough. infection, mainly due to a virus, and is often cured spontaneously or relieved by antitussive drugs within 3 weeks of onset. In clinical settings, however, we often encounter patients who are difficult to diagnose and treat due to complicated causes, such as in cases of asthma on its own or in combination with an infection. In cases where symptoms other than cough are minor, differential diagnosis is often difficult.

Measurement of the fraction of exhaled nitric oxide (FeNO) is useful for the diagnosis of asthma and cough variant asthma (CVA) (2); however, there are only a few reports on the evaluation of FeNO with respect to the diagnosis of acute cough. Many patients who visit a medical clinic with a chief complaint of cough do so within three weeks of onset (3). This acute cough can, in fact, have many causes potentially leading to chronic cough, such as asthma. In this study, we retrospectively examined the utility of FeNO in the differential diagnosis of infectious and asthmatic cough [typical asthma/coughpredominant asthma (CPA)/CVA] in patients with acute cough and asthmatic episodes.

\section{Patients and Methods}

Participants. We retrospectively analyzed 80 patients who visited Nakajima Medical Clinic with the chief complaint of acute cough accompanied by nocturnal sleep disturbance, as well as prolonged or chronic cough episodes, such as asthmatic cough. The inclusion criteria for patients with asthmatic episodes were as follows: i) patients who have experienced at least two prolonged/chronic cough episodes in the past due to respiratory tract infection, ii) patients who experience nocturnal sleep disturbance due to cough in the early morning and at night, and iii) patients with cough-inducible factors, such as a cold, tobacco smoke (perfume), fatigue or stress (4). All patients underwent: i) chest X-ray photographs, ii) blood sampling tests, iii) pulmonary function tests, and iv) FeNO measurement tests $\left(\mathrm{NIOX} \mathrm{MINO}^{\circledR}\right.$, Chest) at the first visit. This survey was approved by the review board of the Hyogo Prefecture Medical Association (R3-002). 
Table I. Patient baseline characteristics.

\begin{tabular}{|c|c|c|c|}
\hline & $\begin{array}{l}\text { Asthma } \\
(\mathrm{N}=24)\end{array}$ & $\begin{array}{l}\text { Asthma/Infection } \\
\qquad(\mathrm{N}=39)\end{array}$ & $\begin{array}{l}\text { Infection } \\
(\mathrm{N}=17)\end{array}$ \\
\hline Gender (male/female) & $7 / 17$ & $9 / 30$ & $5 / 12$ \\
\hline Age, years & $39.7 \pm 12.9$ & $38.4 \pm 12.7$ & $45.6 \pm 15.3$ \\
\hline $\mathrm{BMI}, \mathrm{kg} / \mathrm{m}^{2}$ & $21.0 \pm 2.6$ & $21.3 \pm 2.6$ & $19.6 \pm 2.8$ \\
\hline Asthma/CPA or CVA & $1 / 23$ & $12 / 27$ & $0 / 0$ \\
\hline $\mathrm{FVC}(\mathrm{L})$ & $3.71 \pm 0.90$ & $3.45 \pm 0.83$ & $2.96 \pm 1.47$ \\
\hline FEV1 (L) & $2.94 \pm 0.61$ & $2.84 \pm 0.69$ & $2.65 \pm 1.41$ \\
\hline FEV1/FVC (\%) & $80.2 \pm 7.6$ & $82.7 \pm 7.1$ & $83.8 \pm 1.2$ \\
\hline $\mathrm{WBC}(/ \mu \mathrm{l})$ & $6,268 \pm 1,195$ & $6,703 \pm 1,615$ & $6,350 \pm 1,447$ \\
\hline Eosinophil (\%) & $4.4 \pm 4.6$ & $4.0 \pm 3.0$ & $3.8 \pm 4.7$ \\
\hline $\begin{array}{l}\text { Total serum IgE } \\
(\mathrm{IU} / \mathrm{ml})\end{array}$ & $191(2-787)$ & $480(2-6,290)$ & $62(2-322)$ \\
\hline $\begin{array}{l}\text { Allergic rhinitis } \\
\text { (yes/no) }\end{array}$ & $17 / 7(70.8 \%)$ & $35 / 4(89.7 \%)$ & $11 / 6(64.7 \%)$ \\
\hline PNDS (yes/no) & $9 / 15$ & $6 / 33$ & $4 / 13$ \\
\hline
\end{tabular}

BMI: Body mass index; CPA: cough-predominant asthma; CVA: coughvariant asthma; FVC: forced vital capacity; FEV1: forced expiratory volume in one second; WBC: white blood cell; IgE: immunoglobulin E; PNDS: post-nasal drip symptoms.

Exclusion criteria. Exclusion criteria for patients were as follows: i) clear acute bronchitis/pneumonia with fever and purulent sputum, ii) inflammatory findings in blood tests, iii) obvious abnormal findings on chest $\mathrm{X}$-ray, iv) sinusitis, v) atypical pathogens (mycoplasma, chlamydia, or whooping cough) infection, vi) a history of pulmonary tuberculosis, vii) ever or current smokers, viii) either asthma, including CPA and CVA, or chronic obstructive pulmonary disease (COPD), ix) a previous diagnosis with gastroesophageal reflux disease (GERD), and $x$ ) intake of angiotensin converting enzyme (ACE) inhibitors.

Diagnosis of asthmatic coughs, including asthma, CPA and CVA. CPA and CVA were defined as cough, which corresponds to one of three points, according to the diagnostic criteria of the "Japanese Guidelines for cough, 2nd edition": i) cough that does not respond to antitussives, ii) cough that responds to short-acting $\beta 2$ agonists (SABA) or long-acting $\beta 2$ agonists (LABA) irrespective of $\mathrm{FeNO}$ values, and iii) cough that responds to inhaled corticosteroids (ICS)/LABA (medium dose or higher dose) and FeNO levels at the first visit were over $22 \mathrm{ppb}$. Asthma was diagnosed when cough was accompanied by obvious wheezing in chest auscultation at the first visit and responded to SABA or LABA, including ICS/LABA.

Diagnosis of infectious cough, including common cold and upper respiratory inflammation. Infectious cough was diagnosed in patients who had cough and sputum accompanied by rhinitis, sore throat, and hoarseness, as well as in patients who responded to antitussives or expectorants.

Clinical analysis. First, we divided the patients into three groups: i) asthmatic cough, ii) infectious cough, and iii) a combination of both, and compared FeNO levels at the first visit and during the cough period. Asthmatic cough was treated with LABA alone or ICS/LABA. For cough evaluation, the patient expressed their cough

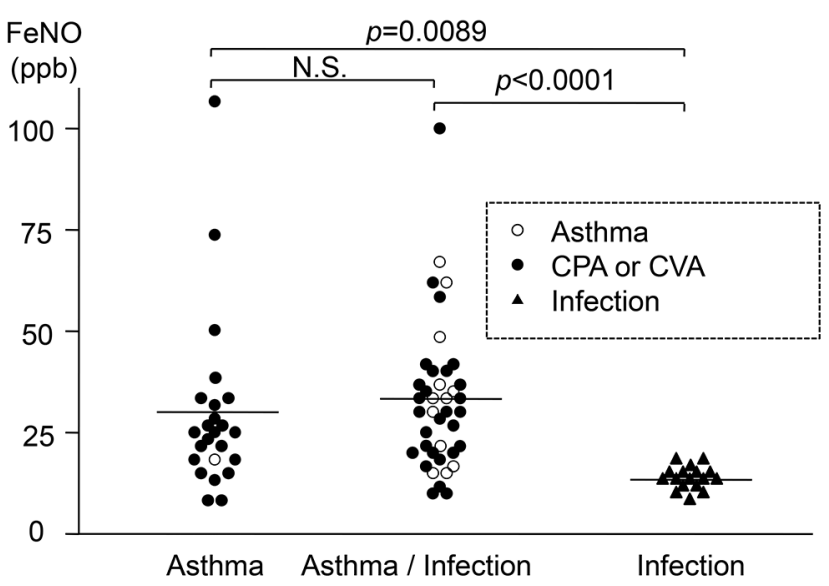

Figure 1. Values of FeNO. The asthmatic cough group and the asthmatic/infectious cough group showed significantly higher FeNO values than the infectious cough group, but there was no significant difference between the asthmatic and the asthmatic/infectious cough group. FeNO: Fraction of exhaled nitric oxide; N.S.: not significant.

state based on the cough score, and when the cough score reached 0 , the cough was considered to have disappeared (5).

Statistical analysis. Measured values are presented as the mean \pm standard deviation (SD). For comparison of the three groups, the Mann-Whitney $U$-test was performed. A two-tailed $p$-Value of less than 0.05 was considered significant.

\section{Results}

Study participants. Of our patient cohort $21 \%$ had infectious cough alone, $30 \%$ had asthmatic cough alone and $49 \%$ had a combination of infectious and asthmatic cough. Table I shows the patient characteristics in the three groups. The patient characteristics of each group were well balanced.

FeNO. The values of FeNO in the asthmatic (30.4 $\pm 24.7 \mathrm{ppb})$ and asthmatic/infectious cough $(33.2 \pm 17.4 \mathrm{ppb})$ were significantly higher than those of the infectious cough $(13.7 \pm 3.2 \mathrm{ppb}) \quad(p=0.0089$ and $p<0.0001$, respectively) (Figure 1); however, there was no significant difference between asthmatic and asthmatic/infectious cough.

Period from start of treatment to cough disappearance. The period from the start of the treatment to the disappearance of cough in the infectious cough group was $7.0 \pm 2.8$ days, which was significantly shorter than the $12.3 \pm 6.1$ days in the asthmatic cough group and the $12.0 \pm 7.2$ days in the asthmatic/infectious cough group ( $p=0.0079$ and $p<0.0018$, respectively). On the other hand, there was no significant difference in the period duration 


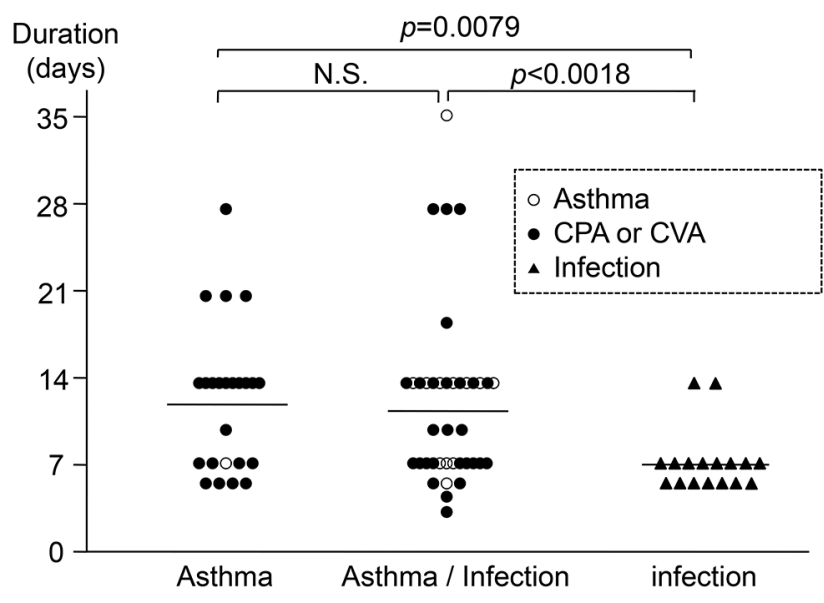

Figure 2. Duration from start of treatment to cough disappearance. The asthma cough group and the asthma/infection cough group showed a significantly longer disease duration compared to the infection cough group, but there was no significant difference between the asthma cough group and the asthma/infection cough group. CPA: Cough-predominant asthma; CVA: cough-variant asthma; N.S.: not significant.

from the start of the treatment to cough disappearance between the asthmatic cough and the asthmatic/infectious cough group (Figure 2). Since the FeNO value in the asthmatic cough was high, further investigation for clarifying whether there was any correlation between the FeNO value and the treatment period did not show any significance (Figure 3).

\section{Discussion}

This study was conducted at a clinic that deals with many patients with acute cough and differs from hospitals that deal with many referral patients. Since we limited the subjects to patients who had asthmatic episodes in the initial interview, $75.9 \%$ of patients had asthmatic cough, which differed from the $28 \%$ reported by Yamasaki et al. (1). Intriguingly, although we excluded patients with obvious infections, such as those presenting with fever and purulent sputum, and limited subjects to patients with asthmatic episodes, the rate of infectious cough was comparable with that reported previously (1). In other words, even if an asthmatic disorder is suspected as the cause of cough, clinicians should pay attention to the complications of infectious disease when examining patients with an acute cough.

According to the Japanese Guidelines for Cough, $2^{\text {nd }}$ edition, the diagnoses of CPA and CVA in this study were based on the principle that bronchodilators should be effective. Since approximately $30 \%$ of patients with CVA are reported to have typical bronchial asthma with wheezing (68 ) and to undergo remodeling, seen in typical bronchial

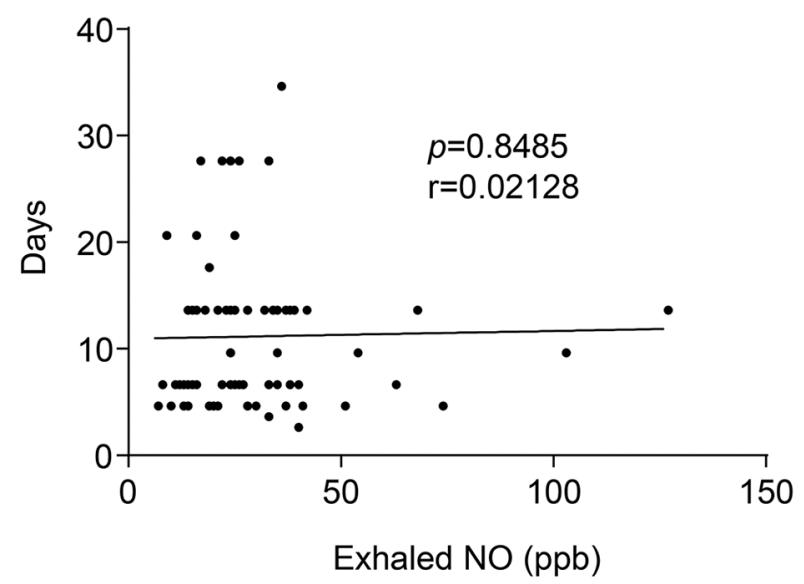

Figure 3. A correlation between the fraction of exhaled NO value and the treatment period. There was no significant correlation between the two variables.

asthma (9), early diagnosis and treatment are important even for acute cough. It has been reported that ICS can prevent progression to typical asthma $(8,10,11)$, thus, ICS/LABA is often used for CVA treatment.

Concerning chronic cough, it has been reported that $40 \%$ $50 \%$ of patients with CPA or CVA show low levels of FeNO (12). While the bronchodilation effect is often judged by the response to the ICS/LABA combination drug, the FeNO measurement test that can easily determine the result in a few minutes is not an essential requirement in the Japanese Guidelines for cough, $2^{\text {nd }}$ edition. If the FeNO level is high, CPA or CVA can easily be diagnosed, showing an eosinophilic airway inflammation. However, in this study, there was a relatively high number of cases with low FeNO levels among patients diagnosed with asthmatic cough.

Kharitonov et al., have reported that FeNO levels in healthy individuals increase due to upper respiratory tract infection and decrease to normal levels during the 3-week recovery period (13). Although in this study FeNO levels increased in asthmatic diseases there were no significant differences between asthmatic and asthmatic/infectious cough. Our results differ from those of Kharitonov et al., and further investigation is necessary to clarify the underlying reasons.

Viral infection is an important risk factor for the exacerbation of asthma (14). In particular, during rhinovirus infection, the presence of the virus is confirmed not only in the upper, but also in the lower respiratory tract, where a direct influence of the viral infection on it can be speculated (15). Although it has also been reported that rhinovirus 
infection prolongs the treatment duration of asthmatic patients (16), in this study, airway infection did not prolong the treatment duration of asthmatic patients. This suggests that it is important to treat asthma with ICS, even if the patient has a minor respiratory tract infection.

In conclusion, we showed that FeNO measurement is useful for the differential diagnosis of patients with acute cough. Despite this, it should be noted that the FeNO value varied in the asthmatic cough group and that the treatment period could not be estimated using FeNO.

\section{Conflicts of Interest}

The Authors state that they have no conflicts of interest in relation to this study.

\section{Authors' Contributions}

TakN, TatN and TerN wrote the manuscript. TakN made the database. TakN, KN and YN conceived study design. TatN conducted the statistical analysis. All Authors analyzed the data, conceived the study, read and approved the final manuscript.

\section{Acknowledgements}

We sincerely thank all the participants. We would like to thank Editage (www.editage.com) for English language editing.

\section{References}

1 Yamasaki A, Hanaki K, Tomita K, Watanabe M, Hasagawa Y, Okazaki R, Yamamura M, Fukutani K, Sugimoto Y, Kato K, Kodani M, Ikeda T, Konishi T, Kawasaki Y, Tokuyasu H, Yajima $\mathrm{H}$, Sejima H, Isobe $\mathrm{T}$ and Shimizu E: Cough and asthma diagnosis: physicians' diagnosis and treatment of patients complaining of acute, subacute and chronic cough in rural areas of Japan. Int J Gen Med 3: 101-107, 2010. PMID: 20463827. DOI: $10.2147 /$ ijgm.s8167

2 Karrasch S, Linde K, Rücker G, Sommer H, Karsch-Völk M, Kleijnen J, Jörres RA and Schneider A: Accuracy of FENO for diagnosing asthma: a systematic review. Thorax 72(2): 109-116, 2017. PMID: 27388487. DOI: 10.1136/thoraxjnl-2016-208704

3 Otoshi T, Nagano T, Funada Y, Takenaka K, Nakata H, Ohnishi H, Nishiuma T, Nakajima T, Kageshita T, Tsuchiya T, Yamamoto M, Kobayashi K and Nishimura Y: A cross-sectional survey of the clinical manifestations and underlying illness of cough. In Vivo 33(2): 543-549, 2019. PMID: 30804139. DOI: 10.21873/ invivo. 11508

4 Matsumoto H, Tabuena RP, Niimi A, Inoue H, Ito I, Yamaguchi M, Otsuka K, Takeda T, Oguma T, Nakaji H, Tajiri T, Iwata T, Nagasaki T, Jinnai M, Matsuoka H and Mishima M: Cough triggers and their pathophysiology in patients with prolonged or chronic cough. Allergol Int 61(1): 123-132, 2012. PMID: 22377525. DOI: 10.2332/allergolint.10-OA-0295

5 Shioya T, Ito N, Watanabe A, Kagaya M, Sano M, Shindo T, Miura S, Kimura $\mathrm{K}$ and Miura M: Antitussive effect of azelastine hydrochloride in patients with bronchial asthma. Arzneimittelforschung 48(2): 149-153, 1998. PMID: 9541725.
6 Fujimura M, Nishizawa Y, Nishitsuji M, Nomura S, Abo M and Ogawa H: Predictors for typical asthma onset from cough variant asthma. J Asthma 42(2): 107-111, 2005. PMID: 15871442.

7 Nakajima T, Nishimura Y, Nishiuma T, Kotani Y, Funada Y, Nakata $\mathrm{H}$ and Yokoyama M: Characteristics of patients with chronic cough who developed classic asthma during the course of cough variant asthma: a longitudinal study. Respiration 72(6): 606-611, 2005. PMID: 16113512. DOI: 10.1159/000087459

8 Matsumoto $\mathrm{H}$, Niimi A, Takemura M, Ueda T, Tabuena R, Yamaguchi M, Matsuoka H, Hirai T, Muro S, Ito Y, Mio T, Chin $\mathrm{K}$, Nishiyama $\mathrm{H}$ and Mishima M: Prognosis of cough variant asthma: a retrospective analysis. J Asthma 43(2): 131-135, 2006. PMID: 16517429. DOI: 10.1080/02770900500498477

9 Birring SS, Prudon B, Carr AJ, Singh SJ, Morgan MD and Pavord ID: Development of a symptom specific health status measure for patients with chronic cough: Leicester Cough Questionnaire (LCQ). Thorax 58(4): 339-343, 2003. PMID: 12668799. DOI: 10.1136/thorax.58.4.339

10 Cheriyan S, Greenberger PA and Patterson R: Outcome of cough variant asthma treated with inhaled steroids. Ann Allergy 73(6): 478-480, 1994. PMID: 7998659.

11 Fujimura M, Ogawa H, Nishizawa Y and Nishi K: Comparison of atopic cough with cough variant asthma: is atopic cough a precursor of asthma? Thorax 58(1): 14-18, 2003. PMID: 12511712. DOI: $10.1136 /$ thorax.58.1.14

12 Asano T, Takemura M, Fukumitsu K, Takeda N, Ichikawa H, Hijikata H, Kanemitsu Y, Uemura T, Takakuwa O, Ohkubo H, Maeno K, Ito Y, Oguri T, Nakamura A and Niimi A: Diagnostic utility of fractional exhaled nitric oxide in prolonged and chronic cough according to atopic status. Allergol Int 66(2): 344-350, 2017. PMID: 27693513. DOI: 10.1016/j.alit.2016.08.015

13 Kharitonov SA, Yates D and Barnes PJ: Increased nitric oxide in exhaled air of normal human subjects with upper respiratory tract infections. Eur Respir J 8(2): 295-297, 1995. PMID: 7538934. DOI: $10.1183 / 09031936.95 .08020295$

14 Jackson DJ, Sykes A, Mallia P and Johnston SL: Asthma exacerbations: origin, effect, and prevention. J Allergy Clin Immunol 128(6): 1165-1174, 2011. PMID: 22133317. DOI: 10.1016/j.jaci.2011.10.024

15 Mosser AG, Vrtis R, Burchell L, Lee WM, Dick CR, Weisshaar E, Bock D, Swenson CA, Cornwell RD, Meyer KC, Jarjour NN, Busse WW and Gern JE: Quantitative and qualitative analysis of rhinovirus infection in bronchial tissues. Am J Respir Crit Care Med 171(6): 645-651, 2005. PMID: 15591468. DOI: 10.1164/rccm.200407-970OC

16 Wark PA, Johnston SL, Bucchieri F, Powell R, Puddicombe S, Laza-Stanca V, Holgate ST and Davies DE: Asthmatic bronchial epithelial cells have a deficient innate immune response to infection with rhinovirus. J Exp Med 201(6): 937-947, 2005. PMID: 15781584. DOI: $10.1084 /$ jem.20041901

Received September 1, 2021 Revised September 21, 2021 Accepted October 5, 2021 